\title{
The Central Role of Ligand Conjugation for Properties of Coordination Complexes as Hole-Transport Materials in Perovskite Solar Cells
}

Wei Zhang, ${ }^{a}$ Yong Hua, ${ }^{a}$ Linqin Wang, ${ }^{\mathrm{b}}$ Biaobiao Zhang, ${ }^{\mathrm{b}}$ Yuanyuan Li, ${ }^{\mathrm{c}}$ Peng Liu, ${ }^{\mathrm{a}}$ Valentina Leandri, Yu Guo, ${ }^{a}$ Hong Chen, ${ }^{b}$ James M. Gardner, ${ }^{a}$ Licheng Sun, ${ }^{\text {b d }}$ and Lars Kloo ${ }^{a^{*}}$

a) Department of Chemistry, Applied Physical Chemistry, KTH Royal Institute of Technology, SE-10044 Stockholm, Sweden

b) Department of Chemistry, Organic Chemistry, KTH Royal Institute of Technology, SE-10044 Stockholm, Sweden

c) Wallenberg Wood Science Center, Department of Fiber and Polymer Technology, KTH Royal Institute of Technology, SE-10044 Stockholm, Sweden

d) State Key Laboratory of Fine Chemicals, DUT-KTH Joint Research Center on Molecular Devices, Dalian University of Technology (DUT), 116024 Dalian, China

*E-mail: Larsa@kth.se 


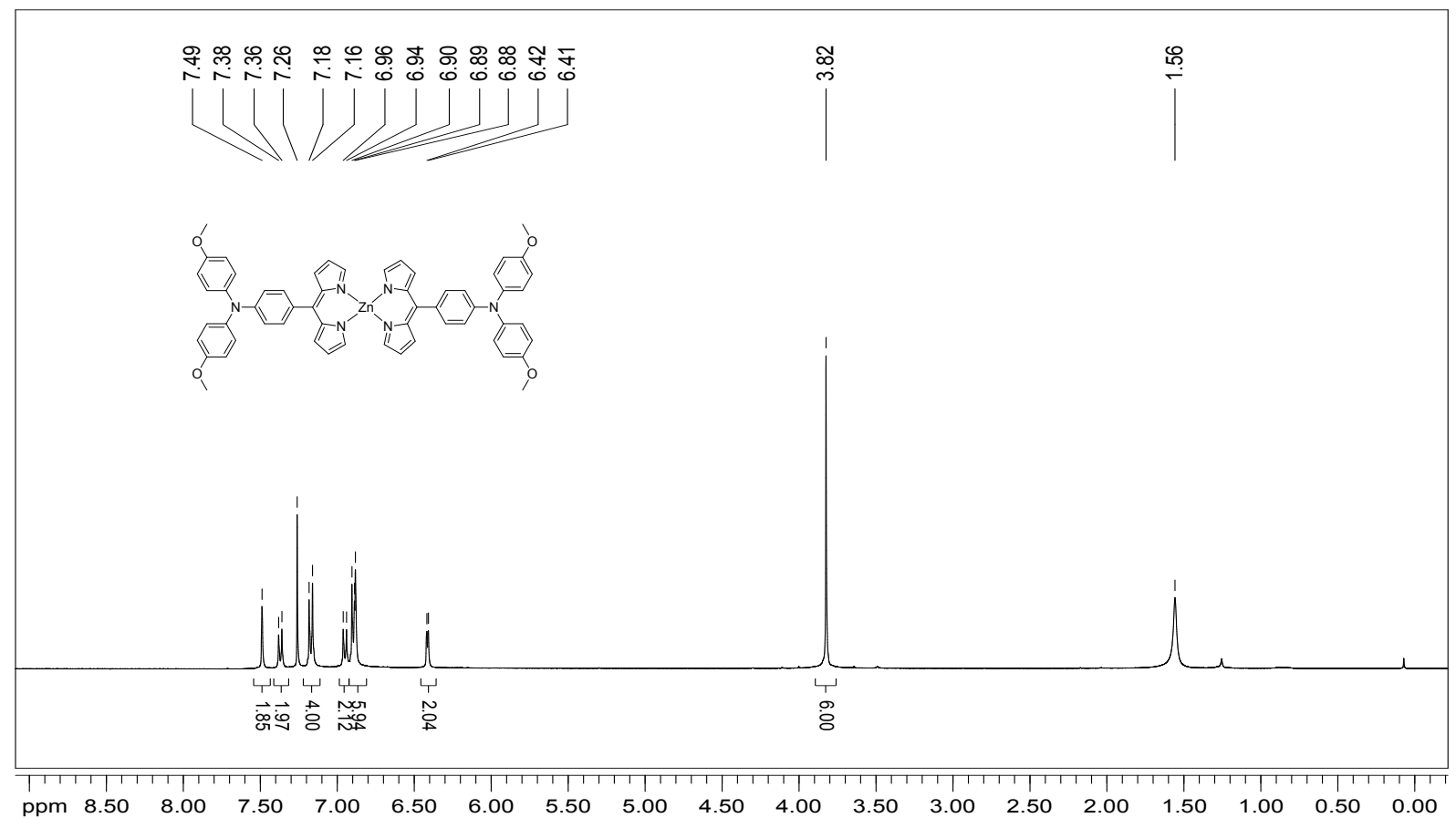

Figure $\mathbf{S 1}{ }^{1} \mathrm{H}$ NMR of $\mathbf{Y 3}$ in $\mathrm{CDCl}_{3}$

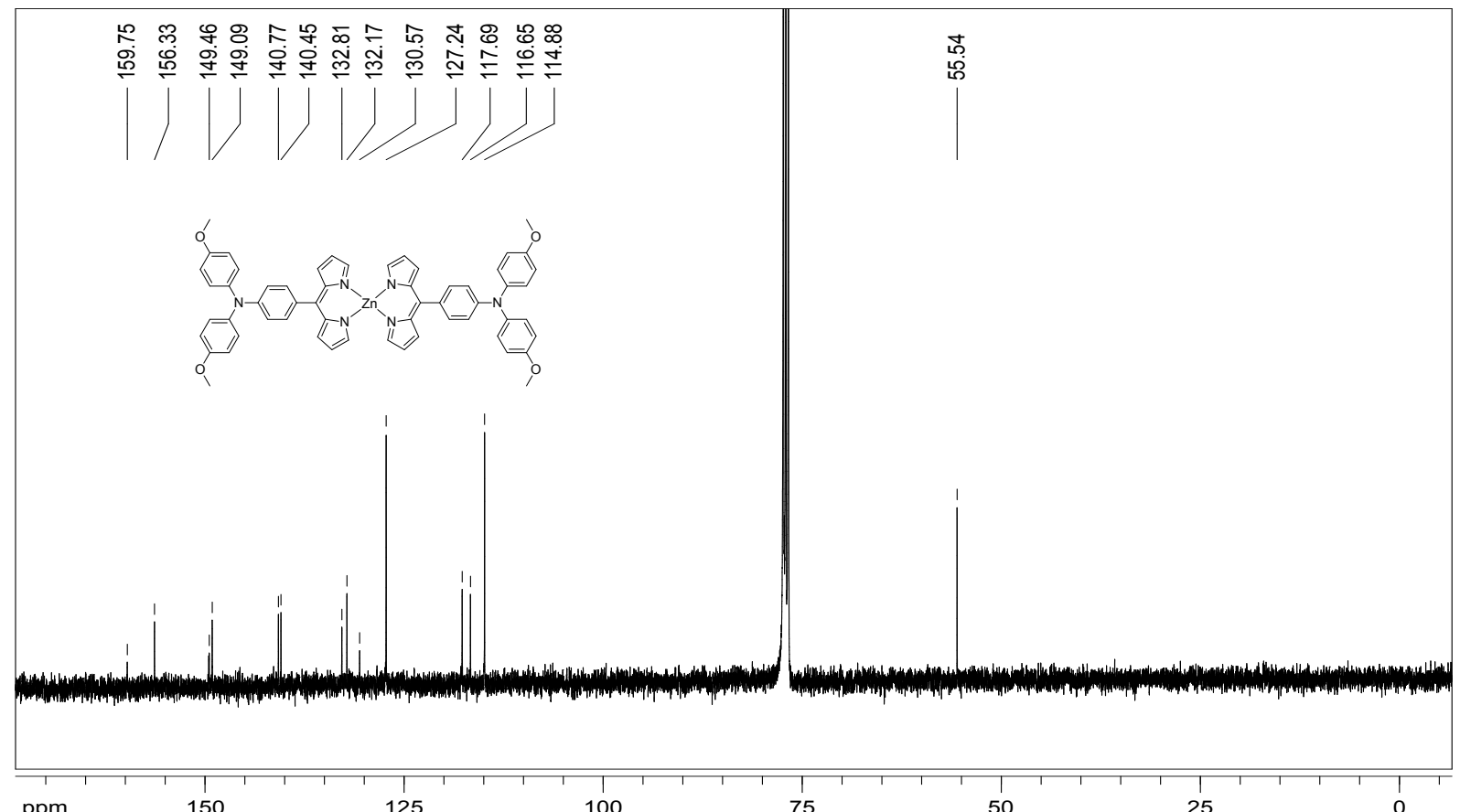

Figure $\mathbf{S 2}{ }^{13} \mathrm{C}$ NMR of $\mathbf{Y 3}$ in $\mathrm{CDCl}_{3}$ 


\section{LJJ-3}

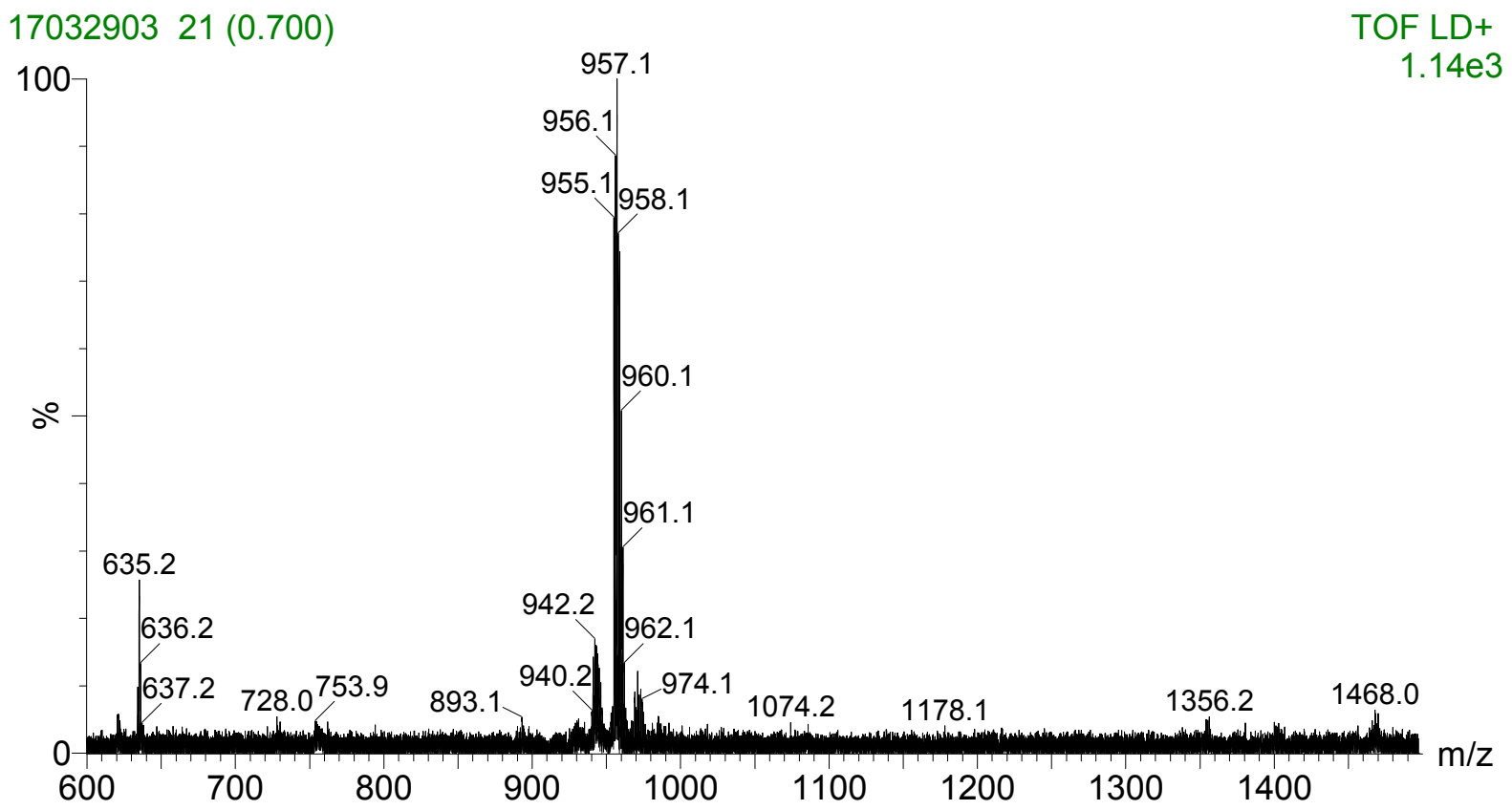

Figure S3 Mass spectrum of Y3.

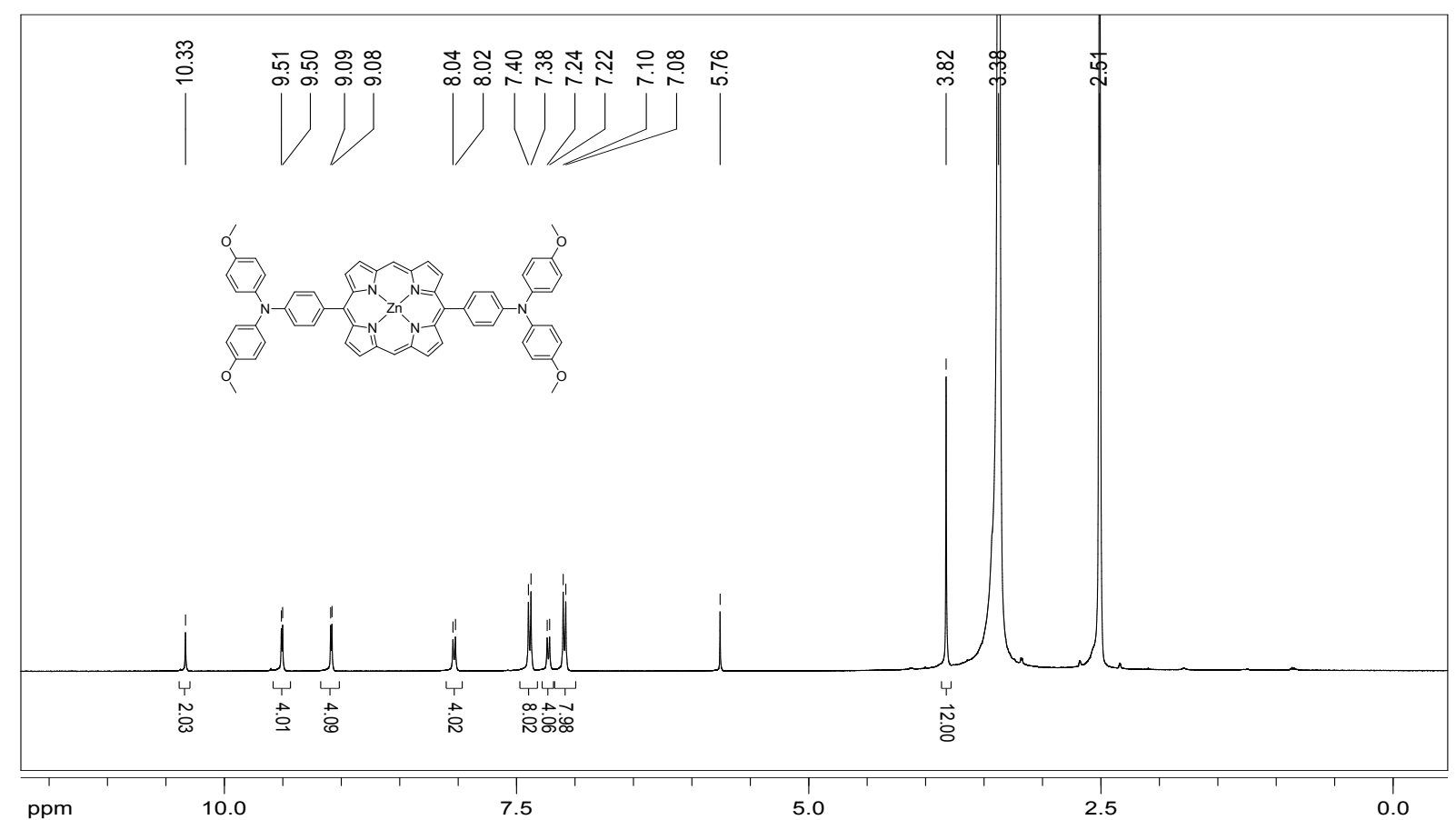

Figure $\mathbf{S 4}{ }^{1} \mathrm{H}$ NMR of $\mathbf{Y 4}$ in d6-DMSO 


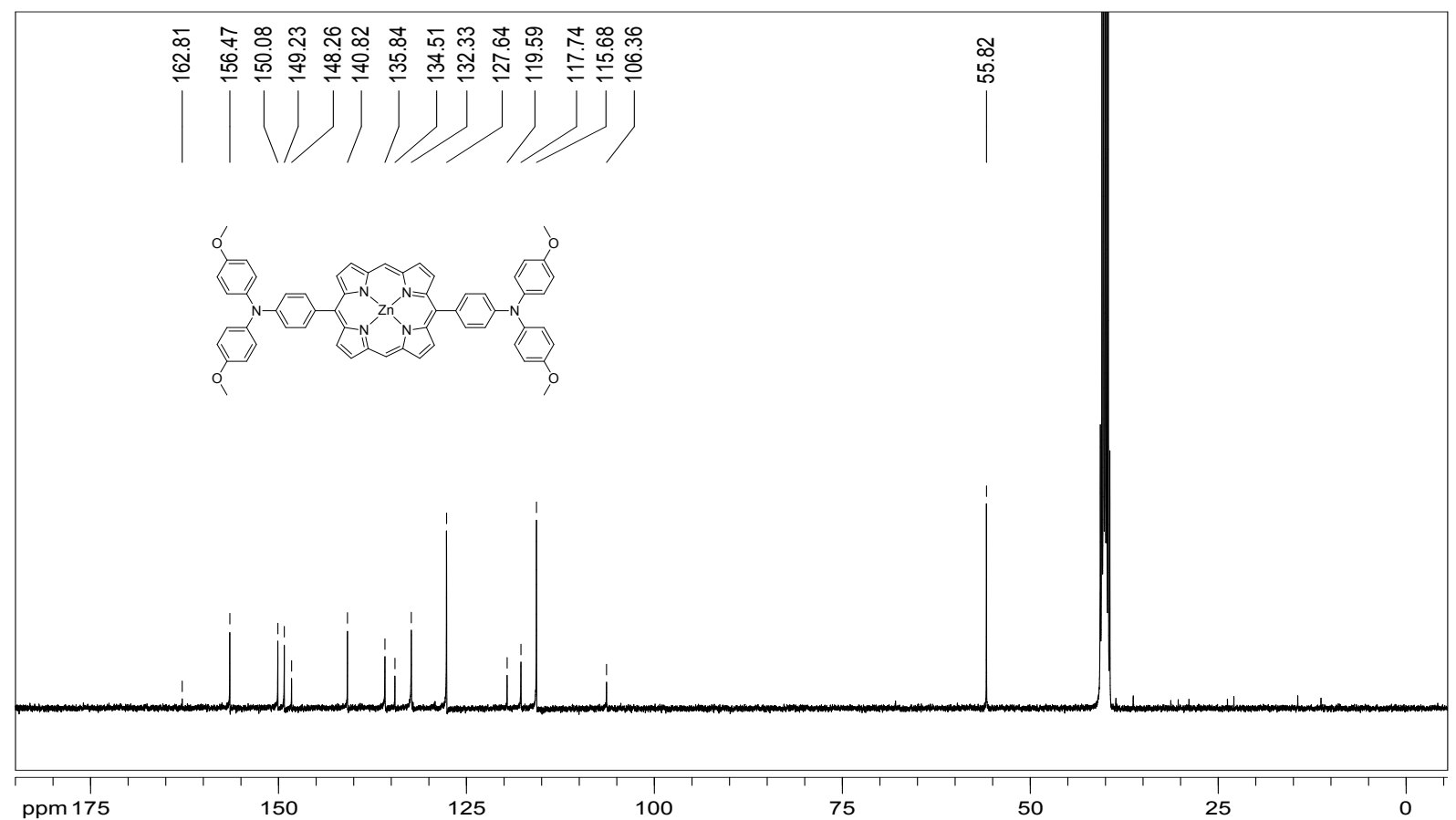

Figure S5 ${ }^{13} \mathrm{C}$ NMR of Y4 in d6-DMSO

\section{LJJ-4}

1703290447 (1.565)

100

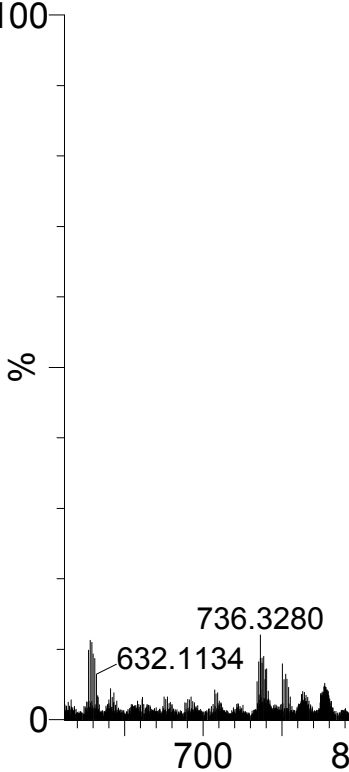

Figure S6 Mass spectrum of Y4. 


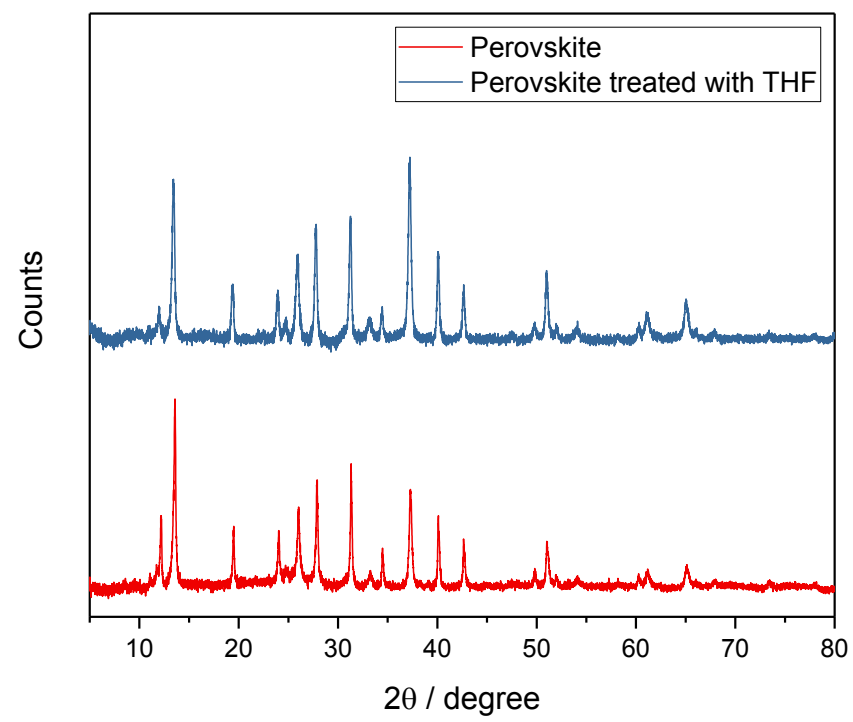

Figure S7 XRD of mixed ion perovskite with and without treatment of THF.

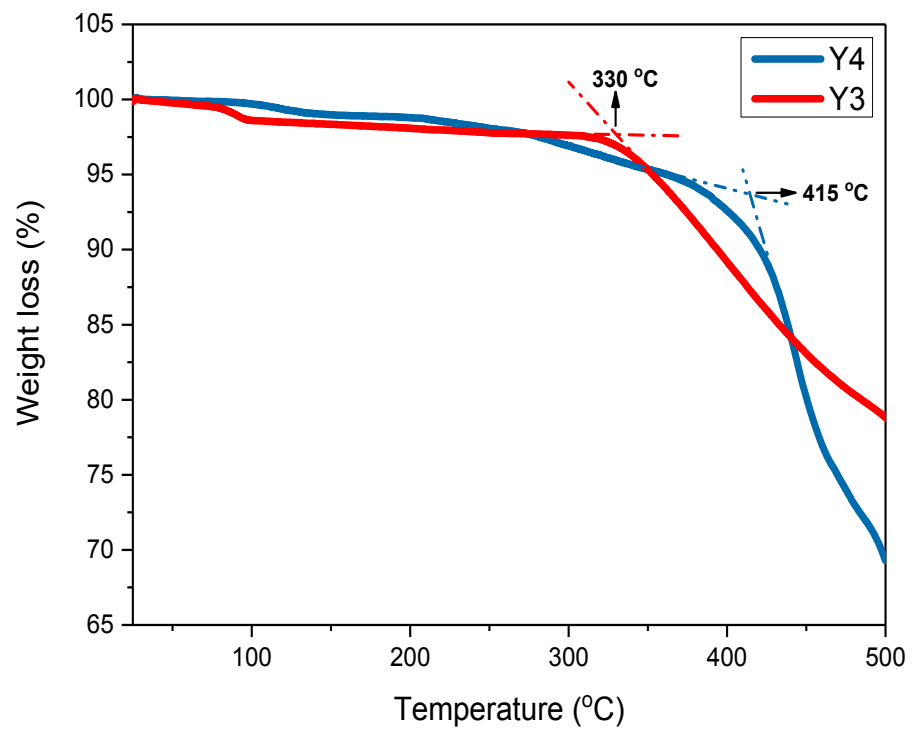

Figure S8 TGA of $\mathbf{Y 3}$ and $\mathbf{Y 4}$ with $50 \mathrm{~mL} / \mathrm{min}_{2}$ atmosphere and $10 \mathrm{~K} / \mathrm{min}$ increase of temperature. 


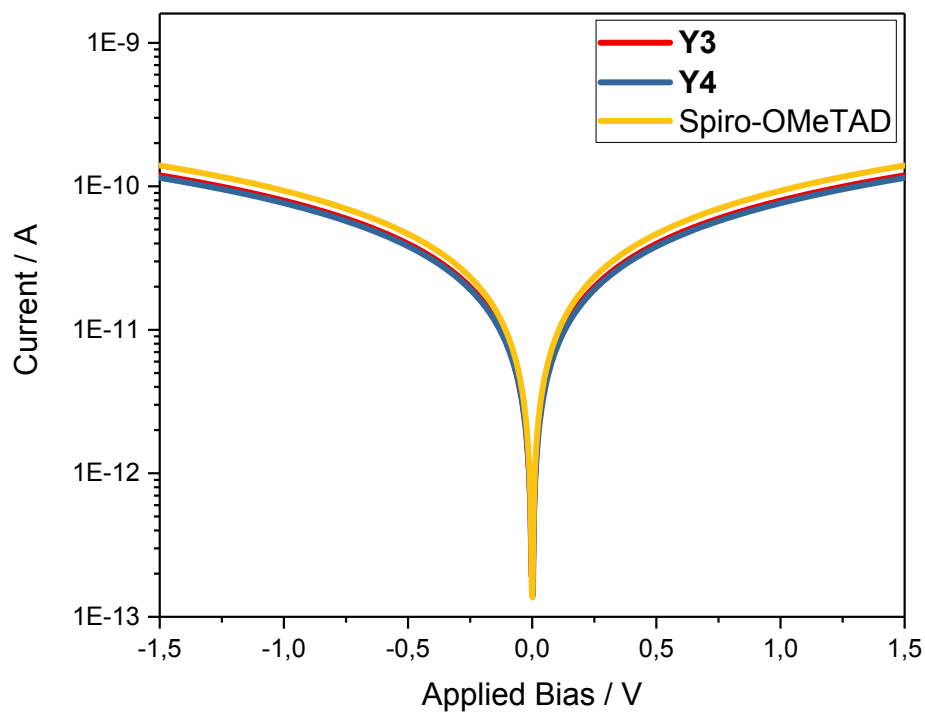

Figure S9 Current-voltage characteristics of the HTM films without doping. 

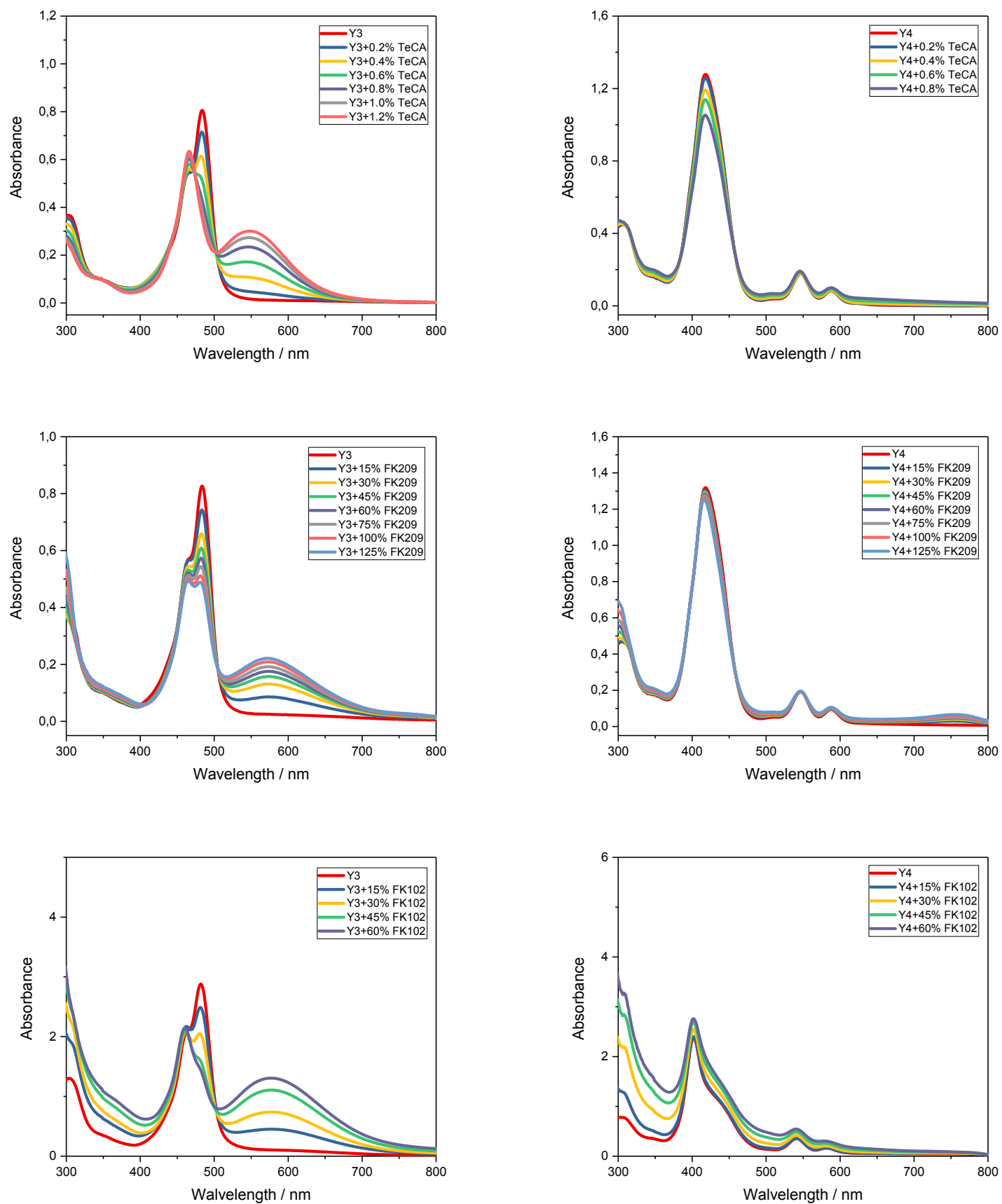

Figure S10 Gradual addition of TeCA, FK209, FK102 as dopants for Y3 and Y4. 


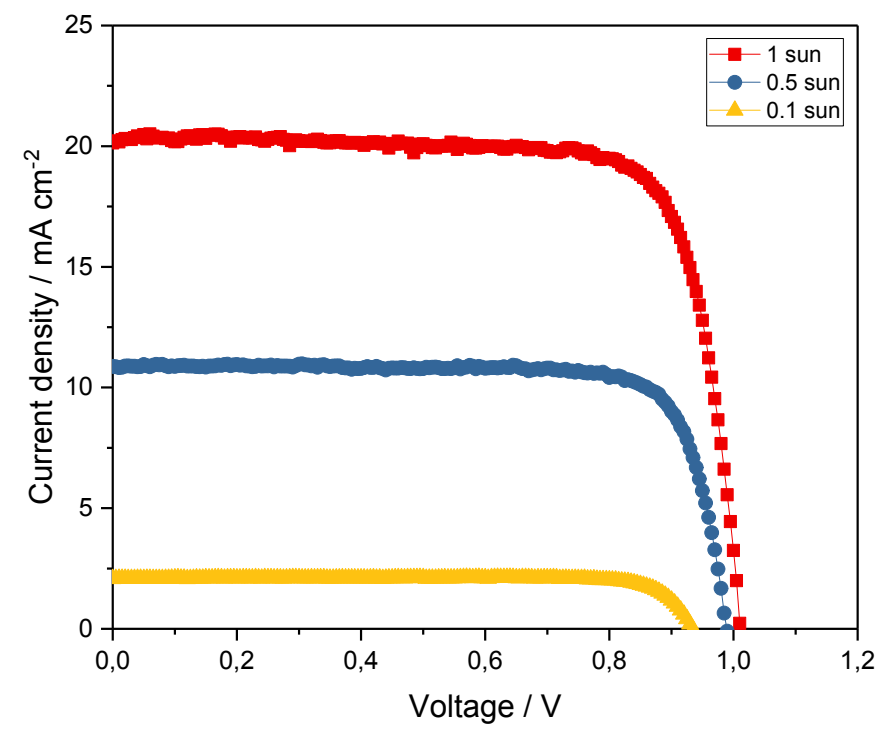

Figure S11 $J-V$ curves of Y4 based PSCs with different light intensity.

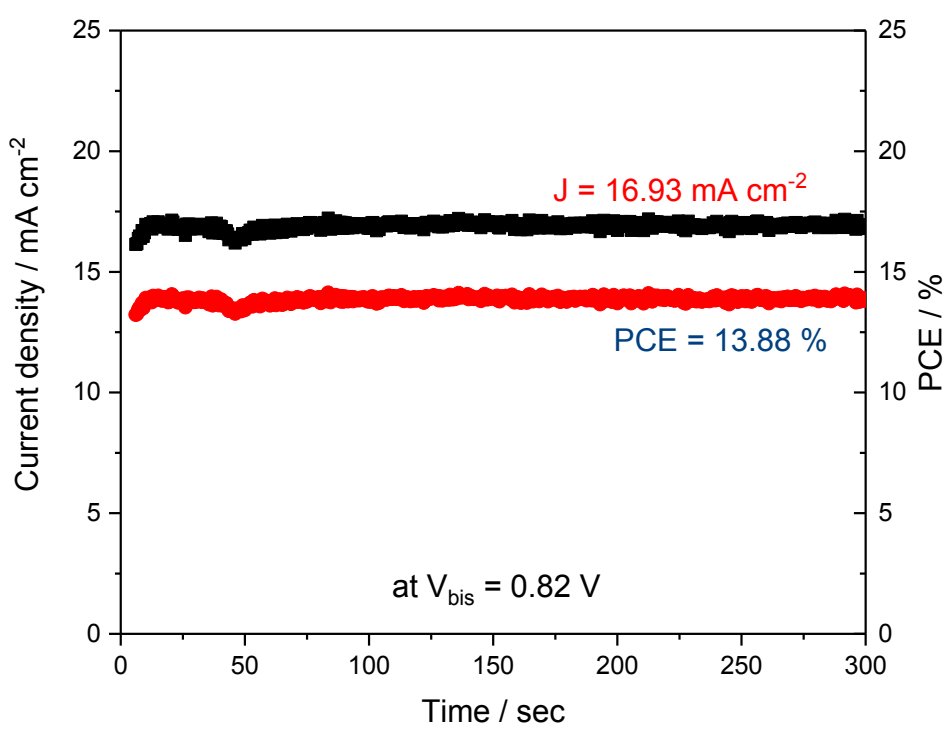

Figure S12 Steady-state output current density and PCE at $0.82 \mathrm{~V}$ of solar cells based on Y4 as holetransport material. 


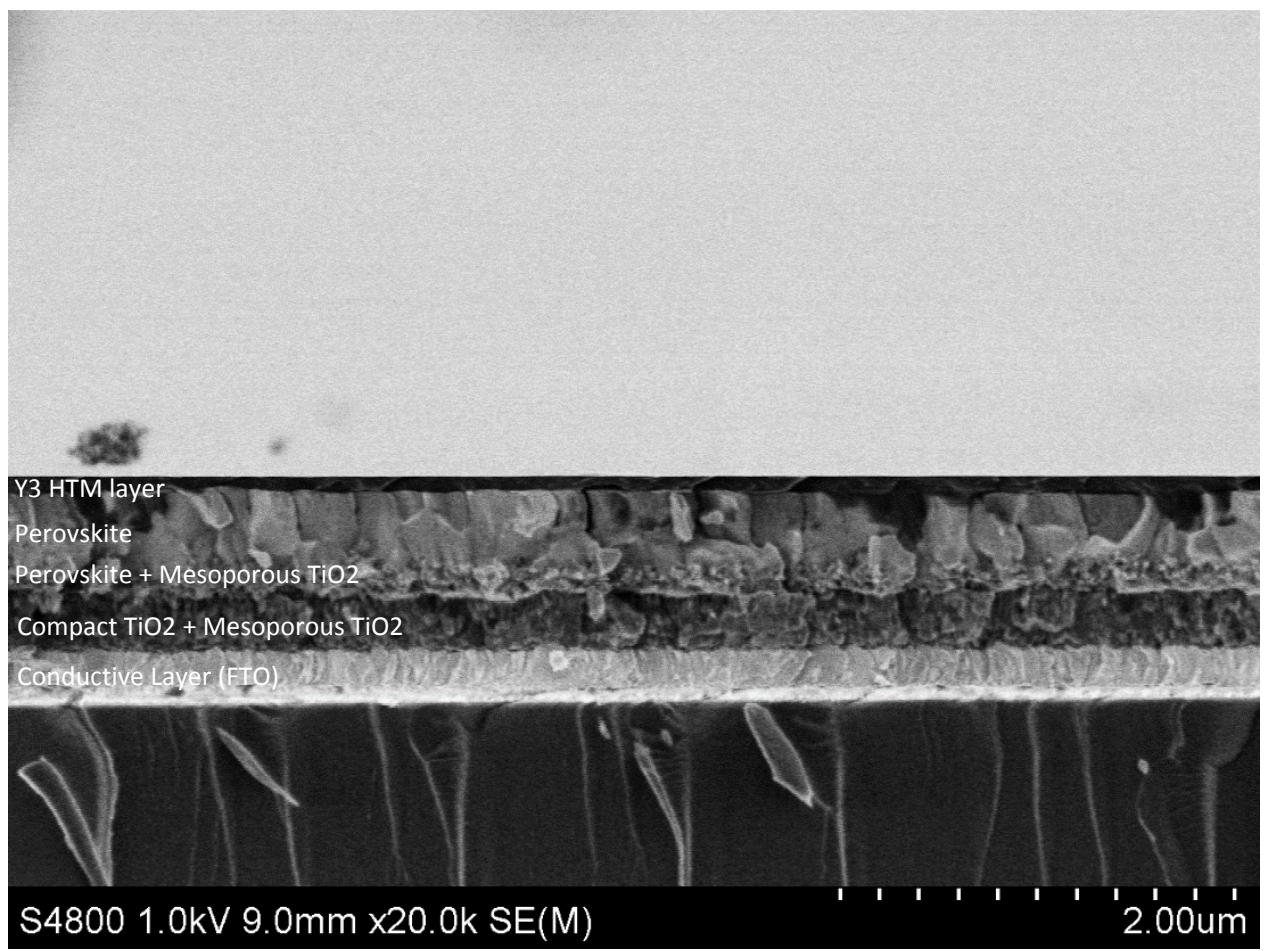

Figure S13 Cross-section SEM image of a device (without $\mathrm{Au}$ ) based on Y3 as hole-transport material.

Table S1 Photovoltaic performance of Y4 based PSCs with different light intensity.

\begin{tabular}{|c|c|c|c|c|}
\hline Light Intensity & $\mathbf{J}_{\mathbf{s c}} / \mathbf{m A} \mathbf{~ c m}^{-\mathbf{2}}$ & $\mathbf{V}_{\text {oc }} / \mathbf{V}$ & $\mathbf{F F}$ & $\mathbf{n} / \boldsymbol{\%}$ \\
\hline 1 sun & 20.13 & 1.01 & 0.79 & 16.05 \\
\hline 0.5 sun & 10.87 & 0.99 & 0.80 & 17.24 \\
\hline 0.1 sun & 2.07 & 0.94 & 0.84 & 16.30 \\
\hline
\end{tabular}

